\title{
Shear Bond Strength Comparison between Conventional Dental Nano Zirconia Combinations and New Functionally Graded Nano Zirconia Combinations after Thermal-Mechanical Cycling
}

\begin{abstract}
T. $\mathrm{SUN}^{a}$, R.F. $\mathrm{LAI}^{a}$, R.Y. $\mathrm{LIU}^{b}$ AND L.Q. SHAO ${ }^{b, *}$
${ }^{a}$ The Medical Centre of Stomatology, the 1st Affiliated Hospital of Jinan University, Guangzhou 510630, China

${ }^{b}$ Department of Stomatology, Nanfang Hospital, Southern Medical University, Guangzhou 510515, China

The aim of the study was to evaluate the core-veneer bond strength of graded zirconia combinations and compared those to conventional zirconia combinations after thermal and mechanical tests. Conventional zirconia-veneer combinations and graded zirconia-veneer combinations were made into cylinders. Prior to shear bond testing, half of each group was subjected to thermal and mechanical cycling testing at three conditional levels. All specimens were thereafter subjected to a shear force. The fractured surfaces were visually analyzed with scanning electron microscopy. The shear bond strength values of functionally graded zirconia combinations were significantly higher than zirconia combinations, irrespective of the fatigue conditions $(P<0.05)$. The shear bond strength values of graded zirconia combinations and zirconia combinations before thermal-mechanical cycling were higher than after $(P<0.05)$. The shear bond strength values of graded zirconia combinations was $40.99 \pm 2.22 \mathrm{MPa}$, $39.44 \pm 2.36 \mathrm{MPa}, 37.45 \pm 2.06 \mathrm{MPa}$, and $36.87 \pm 2.18 \mathrm{MPa}$ for conditions 0 to 3 , respectively. The shear bond strength values were $26.75 \pm 2.16 \mathrm{MPa}, 23.95 \pm 2.16 \mathrm{MPa}, 21.65 \pm 2.14 \mathrm{MPa}$, and $20.49 \pm 2.16 \mathrm{MPa}$ for zirconia combinations from conditions 0 to 3 , respectively. The functionally graded zirconia combinations exhibited greater shear bond strength than zirconia combinations, irrespective of the fatigue conditions. Thermal-mechanical cycling had an impact on the shear bond strength of both graded zirconia combinations and conventional zirconia combinations.
\end{abstract}

DOI: $10.12693 /$ APhysPolA.125.238

PACS: 87.85.jc

\section{Introduction}

Yttrium oxide partially stabilized tetragonal nano zirconia polycrystal (Y-TZP) frameworks exhibit desirable properties, such as chemical and dimensional stability, high mechanical strength, and fracture toughness. Chipping and delamination of the veneering ceramic was reported to be the most frequent reason for failures of zirconia based restorations. For FPDs fabricated with Y-TZP frameworks, the chipping rates of the veneering porcelain were higher than metal ceramic restorations [1].

After cemented in oral cavity, dental restorations were exposed to thermal variations and repeated loading. The incidence of repeated forces during chewing resulted in stress concentration, and thermal variations induced fatigue of the materials themselves and the core-veneer interface [2]. Thermal cycling testing were consequently recommended to simulate the oral conditions prior to mechanical testing [3].

For enhancement of zirconia core materials, studies focused on glass infiltrated zirconia, of which the mechanical properties were reported to be prosperous [4]. In our previous study, a glass-zirconia interlayer was formed through infiltration of $\mathrm{SiO}_{2}-\mathrm{Al}_{2} \mathrm{O}_{3}-\mathrm{K}_{2} \mathrm{O}-\mathrm{Na}_{2} \mathrm{O}$ $\mathrm{CaO}-\mathrm{Tb}_{4} \mathrm{O}_{7}$ glass in zirconia, the coefficient of thermal

*corresponding author; e-mail: shaolongquan@smu.edu.cn expansion (CTE) of which was similar to the veneering ceramic [5]. In one of our unpublished study, the modulus of this glass-zirconia interlayer was proved to be lower than zirconia but higher than the veneering ceramic and the modulus of the interlayer was gradient. We hypothesized the graded glass-zirconia interlayer could enhance the core-veneer bond. The bond strengths of graded zirconia-ceramic combinations were initially analyzed in the previous study, which did not correspond to the clinical conditions in the oral cavity [5]. The bond strengths after thermal and mechanical cycles were further discussed in the present study.

\section{Material and methods}

Eighty Y-TZP blanks (Cercon Base, Densply, Hanau, Hesse-Darmstadt, Germany) were milled in Cercon brain unit then sintered in Cercon heat furnace. The core specimens of each group were made into cylinders $(4.0 \mathrm{~mm}$ in diameter and $4.0 \mathrm{~mm}$ in height) using a metal mold. Half of the core specimens were infiltrated with glass according to the method in our previous study [6]. A layer of liner was then applied on the surface of the core specimens. The veneering ceramics (Cercon Ceram Kiss) were added to the core specimens and built up to a final dimension ( $4.0 \mathrm{~mm}$ in diameter and $4.0 \mathrm{~mm}$ in height). The core-veneer specimens were then fired to full density. Subsequently, glaze firing was applied to all specimens.

Prior to shear test, the specimens were subjected to thermal-mechanical cycling at conditions 0 to $3(n=10)$. The specimens were subjected to thermocycling $(20,000$, 
$6000,12,000$ cycles $)$ in water $\left(5 / 60^{\circ} \mathrm{C}\right)$ with a transfer time of $2 \mathrm{~s}$ in a thermocycling machine (DEJG-018, DEYI Enterprise, Xiamen, Fujian, China). The specimens undergoing thermocycling were thereafter subjected to mechanical cycling testing in a mechanical cycling machine (EnduraTEC ELF3300, EnduraTEC Systems Corporation, Minnetonka, MN, USA). Sliding cycle fatigue was applied with a spherical tungsten carbide indenter $(r=3.18 \mathrm{~mm})$ at $1.6 \mathrm{~Hz}$ in a dry environment during 25,000, 50,000, and 100,000 cycles. Thermal and mechanical conditions were displayed in Table.

TABLE I

Fatigue tests conditions based on the thermal and mechanical number of cycles.

\begin{tabular}{c|c|c|c|c}
\hline \hline & $\begin{array}{c}\text { Condi- } \\
\text { tion 0 }\end{array}$ & $\begin{array}{c}\text { Condi- } \\
\text { tion 1 }\end{array}$ & $\begin{array}{c}\text { Condi- } \\
\text { tion 2 }\end{array}$ & $\begin{array}{c}\text { Condi- } \\
\text { tion 3 }\end{array}$ \\
\hline $\begin{array}{c}\text { thermal cycles } \\
\text { mechanial cycles }\end{array}$ & 0 & 3000 & 6000 & 12,000 \\
& 0 & 25,000 & 50,000 & 100,000
\end{tabular}

Each specimen was mounted in a metal holder on the universal testing machine (AG-IC, Shimadzu, Kyoto, Kyoutofu, Japan). The specimens were fixed in a custom made stainless steel, allowing the load applied at the core-veneer interface (Fig. 1). Load was applied at a crosshead speed of $1 \mathrm{~mm} / \mathrm{min}$ until failure. The ultimate load to failure was recorded by the system's software (Trapezium X, Shimadzu, Kyoto, Kyoutofu, Japan).

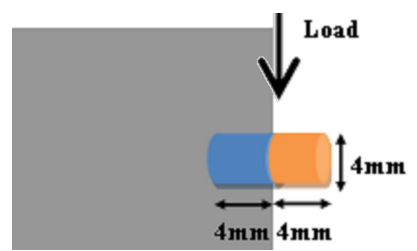

Fig. 1. Cross-section schematic of the shear test device.

The fractured surfaces were visually analyzed with a microscope (LSM 700, Carl Zeiss, Jena, Germany). The surface with remaining veneering ceramic was measured by a software (AnalySIS 3.0 Soft Imaging System, Münster, North Rhine-Westphalia, Germany). This was done by tracing the borders of the cohesive veneer/core fracture that remained within the bonded interface. The fracture patterns were classified as cohesive in the veneer, adhesive at the core-veneer interface, and cohesive in the core. A part of the selected fractured surfaces were observed with SEM (SSX-550, SHIMADZU, Kyoto, Kyoutofu, Japan).

The SBS values were statistically analyzed by the SPSS 13.0 Program (SPSS Inc. Chicago Illinois, USA program). Differences between processing types and fatigue conditions on SBS values were analyzed by 2-way ANOVA $(\alpha=0.05)$.

\section{Results}

Figure 2 showed a plot of the SBS values of graded zirconia combinations and zirconia combinations before

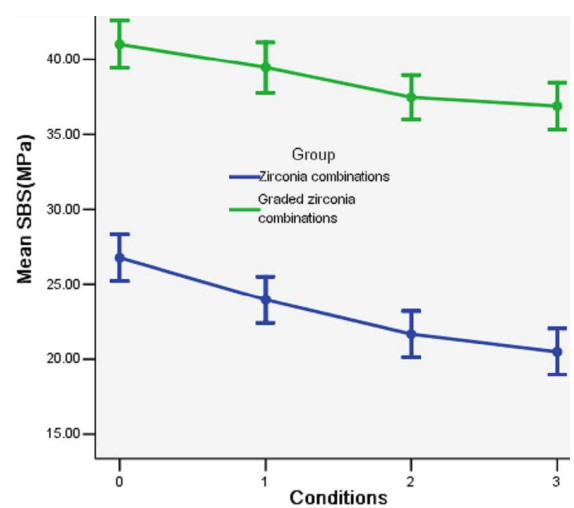

Fig. 2. Mean SBS values after thermal and mechanical cycling.

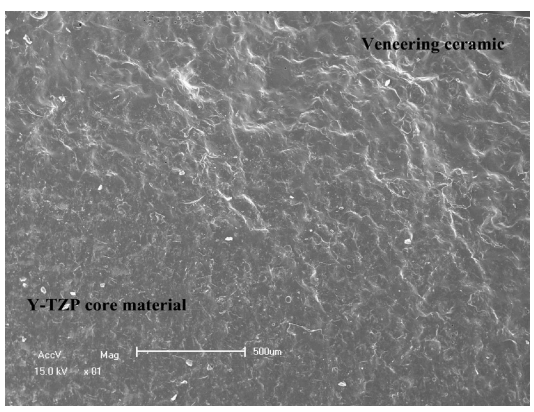

Fig. 3. Fractured interface of zirconia combinations.

and after thermal-mechanical cycling. Table showed that the SBS values of functionally graded zirconia combinations were significantly higher than zirconia combinations, irrespective of the fatigue conditions $(P<0.05)$. The SBS values of graded zirconia combinations were $40.99 \pm 2.22 \mathrm{MPa}, 39.44 \pm 2.36 \mathrm{MPa}, 37.45 \pm 2.06 \mathrm{MPa}$, and $36.87 \pm 2.18 \mathrm{MPa}$ for conditions 0 to 3 , respectively. The SBS values were $26.75 \pm 2.16 \mathrm{MPa}, 23.95 \pm 2.16 \mathrm{MPa}$, $21.65 \pm 2.14 \mathrm{MPa}$, and 20.49 $\pm 2.16 \mathrm{MPa}$ for zirconia combinations for conditions 0 to 3 , respectively. The SBS values of graded zirconia combinations and zirconia combinations before thermal-mechanical cycling were higher than after $(P<0.05)$. The mean SBS values of graded zirconia combinations and zirconia combinations for con-

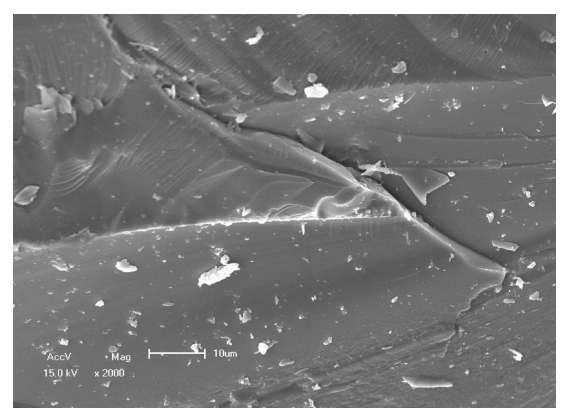

Fig. 4. Fractured veneering ceramic of graded zirconia combinations. 
dition 3 decreased to $4.12 \mathrm{MPa}$ and $6.26 \mathrm{MPa}$, respectively, which represented a bond strength loss of $10 \%$ and $23 \%$ of their initial bond strength values (condition 0 ). After condition 3 fatigue tests, corresponding to the most severe testing conditions, the SBS values of graded zirconia combinations were $80 \%$ higher than that of zirconia combinations.

Zirconia combinations mainly showed adhesive failure at the core-veneer interface (Fig. 3). The main failure mode for graded zirconia combinations was cohesive within the veneering ceramic (Fig. 4).

\section{Discussion}

Shear bond strength test has not been standardized. According to the ISO 11405 standards a loading speed of $0.75( \pm 0.30) \mathrm{mm} / \mathrm{min}$ was recommended for a bonded specimen. The geometry and dimension of the specimens used in this study was similar to the previous study on the assessment of shear bond strength of the ceramic core material and the veneering ceramic [7].

The impact of fatigue test on mechanical properties of zirconia ceramic restorations were widely acknowledged [8]. However, few studies focused on the impact of fatigue test on core-veneer bond of zirconia restorations. Thermal cycling conditions were selected based on a previous study which suggested that 6000 thermal cycles was corresponding to 5 years in clinical service [9]. Thermal cycles of 3000 and 12,000 were then extrapolated for 2.5 years and 10 years of clinical service, respectively. In the present study, the number of cycles was set as 25,000, 50,000 and 100,000. Sartori [10] fixed a number of 100,000 mechanical cyclic testing for dental implants, thus estimating a 5 year period in the oral cavity. Mechanical cycles of 25,000 and 50,000 cycles were therefore equal to 1.25 and 2.5 years of clinical service, respectively.

The shear test results showed that the new functionally graded combinations exhibited significantly higher SBS values than zirconia combinations, irrespective of fatigue testing conditions $(p<0.05)$.

The new functionally graded zirconia combinations were also proved to be less affected by fatigue tests than zirconia ones. Underwent the most aggressive testing conditions (condition 3 ) the bond loss was $10 \%$ for graded zirconia combinations and $23 \%$ for zirconia combinations. The stresses generated by thermal cycling tests were considered to increase the occurrence of degradation in wet and aqueous environments, and also to encourage the effect of mechanical fatigue, which weakened the materials and their interfaces [11]. The fair fatigue behavior of graded zirconia combinations resulted from the effect of zirconia-glass graded transition. The bond strength could be weakened by residual stresses as a result of veneer and core CTE mismatch [6]. The graded zirconia core and the veneering ceramic with similar CTE could generate compressive stresses in the weaker veneering ceramics, therefore reinforcing the overall strength of the restoration.
In assessment of the findings in this study, failure mode should also be taken into consideration. Failures primarily occurred at the core-veneer interface for the zirconia combinations that was comparable to the results of other laboratory studies $[12,13]$. This could be interpreted as a poor core-veneer bond. The main failure mode of graded zirconia combinations was cohesive in the veneering ceramic which could explain as a better bond of graded zirconia core material and the veneer ceramic. The typical views of the fractured surface were showed in Fig. 3 and Fig. 4.

\section{Conclusions}

The functionally graded zirconia combinations exhibited greater shear bond strength values than zirconia combinations, irrespective of the fatigue conditions.

Thermal-mechanical cycling had an impact on the shear bond strength of both graded zirconia combinations and conventional zirconia combinations.

\section{Acknowledgments}

This work was supported by Scientific Cultivation Foundation of the 1st Affiliated Hospital of Jinan University (2013205), Natural Science Foundation of Guangdong Province (9151051501000072), National Natural Science Foundation (31070857) and Open Project Program of Shanghai Institute of Ceramics, Chinese Academy of Sciences (SKL201207SIC).

\section{References}

[1] M. Tsumita, Y. Kokubo, C. Ohkubo, S. Sakurai, S. Fukushima, J. Prosthodont. Res. 54, 102 (2010).

[2] V. Vásquez, M. Ozcan, R. Nishiok, R. Souzaa, A. Mesquita, C. Pavanelli, Dent. Mater. J. 27, 7 (2008).

[3] V.Z. Vásquez, M. Ozcan, E.T. Kimpara, Dent. Mater. 25, 221 (2009).

[4] S.L. Shi, Q.H. Zhang, H.Z Wang, Y.G. Li, Mater Int. 22, 224 (2012).

[5] S.Y. Zhou, L.Q. Shao. J. Ai, C. Hu, L.L. Wang, N. Wen, B. Deng, Adv. Mater. Res 624, 221 (2013).

[6] M.N. Aboushelib, C.J. Kleverlaan, A.J. Feilzer, Dent Mater. 21, 984 (2005).

[7] M. Ishibe, A.J. Raigrodski, B. Flinn, K.H. Chung, C. Spiekerman, R.R. Winter, J. Prosthet. Dent. 106, 29 (2011).

[8] D.K. Oyafuso, M. Ozcan, M.A. Bottino, M.K. Itinoche, Dent. Mater. 24, 351 (2008).

[9] J. Fischer, C. Zbären, B. Stawarczyk, C.H. Hämmerle, J. Dent. 37, 549 (2009).

[10] R. Sartori, C.B. Corrêa, E. Jr. Marcantonio, L.G. Vaz, J. Prosthodont. 18, 130 (2009).

[11] F.C. Lorenzoni, L.M. Martins, N.R. Silva, P.G. Coelho, P.C. Guess, E.A. Bonfante, V.P. Thompson, G. Bonfante, J. Dent. 38, 626 (2010).

[12] P.C. Guess, A. Kuliš, S. Witkowski, M. Wolkewitz, Y. Zhang, J.R. Strub, Dent. Mater. 24, 1556 (2008).

[13] B. Kim, Y. Zhang, M. Pines, V.P. Thompson, Dent. Res. 86, 142 (2007). 